\title{
Labeling of volatile organic compounds emissions from Chinese furniture: Consideration and practice
}

\author{
LIU WeiWei, ZHANG YinPing * \& YAO Yuan \\ Department of Building Science, Tsinghua University, Beijing 100084, China
}

Received November 8, 2012; accepted December 7, 2012

\begin{abstract}
Volatile organic compounds (VOCs) emitted from furniture are recognized as a main cause of bad indoor air quality. In European countries and the U.S., labeling systems for furniture have been established with good effect to address this issue. However, there are problems with these labeling systems. For example, too many VOCs were targeted, and the testing time was too long (7-28 d). Aiming at solving these problems, solutions are put forward to establish furniture VOCs emissions labeling system in China and some practices are introduced in this paper. They are: some furniture popular in the market were tested and main VOCs emitted from these furniture were identified; furniture loading factors in residential homes were surveyed, and reference bedroom and reference living room were established according to the survey results to make emission rate thresholds of furniture; C-history method was developed and applied to testing furniture which could shorten the testing time to $3 \mathrm{~d}$; a reference toluene sample for assessing the precision of the test results of chamber system was prepared. These works are technically helpful for establishing furniture VOCs labeling system in China.
\end{abstract}

indoor air quality (IAQ), formaldehyde, chamber, building environment

Citation: Liu W W, Zhang Y P, Yao Y. Labeling of volatile organic compounds emissions from Chinese furniture: Consideration and practice. Chin Sci Bull, 2013, 58: 3499-3506, doi: 10.1007/s11434-013-5841-z

Volatile organic compounds (VOCs) emissions from indoor decorating and refurbishing materials and furniture are recognized as a main cause of indoor air quality (IAQ) problems [1-4]. Over the past ten years, indoor VOC pollution has been of great concern to the Chinese government. A series of indoor air quality control standards have been promulgated. National standards for indoor environmental pollution control of new buildings GB 50325-2001 [5] and for indoor air quality GB/T 18883-2002 [6] were issued in 2001 and 2002 respectively. National standard GB 503252001 has already been revised as GB 50325-2010. Of the three major strategies are available to solve indoor VOC pollution, pollutant source control, ventilation and air cleaning, pollutant source control is generally the most cost-effective and environmentally preferable [7]. In order to control pollutant sources, labeling schemes of low VOCs emissions products have been established in many countries

*Corresponding author (email: zhangyp@tsinghua.edu.cn) around the world with good effect [8-13]. A labeling scheme following the example of Europe and the U.S. would be a good step toward improving indoor air quality in China. Generally, a VOCs labeling scheme consists of technical, operational and policy parts. Existing labeling schemes target too many VOCs, and require too long a testing time (7-28 d) [8]. China should learn from the advanced countries but not simply copy their labeling systems. We should consider Chinese special features when developing its labeling system: different furniture loading factors, different raw materials, different economical levels etc. This paper focuses on technical part and introduces research thought and research progress, which would serve as supports for establishing furniture VOCs labeling system in China.

\section{Research considerations}

\subsection{Target pollutants}

Hundreds of VOCs are considered target pollutants in 
labeling schemes of Europe and the U.S.. At present, some VOCs are limited in indoor air quality control standards in China. For example, in code for indoor environmental pollution control of civil building engineering GB 50325-2010 [5], only formaldehyde, benzene, toluene, xylene, ethylbenzene and total volatile organic compounds (TVOC) are limited, and formaldehyde, benzene, toluene, xylene, and TVOC are concerned in indoor air quality standard GB/T 188832002 [6]. Furniture is mainly made of wood-based panel, adhesive and paint which can emit lots of VOCs [14-16]. Chinese furniture may be made from different wood-based panel, adhesive and paint than American and European furniture, and therefore emit a different set of VOCs. It is necessary to test furniture in the market in order to determine major VOCs emissions from Chinese furniture.

\subsection{Threshold values}

In recent years, many people in China complain that although they have used furniture that meet national standard GB 18584-2001 [17], the indoor air quality in the room is not acceptable. This suggests that national standards for furniture are inadequate to insure acceptable indoor air quality. There are two reasons for this phenomenon: firstly, national standard GB 18584-2001 uses desiccator method to test furniture, but this method can not obtain real emission performance of the whole furniture under service conditions; secondly, indoor air quality still depends on furniture loading amount in the room. For example, the more furniture loaded in the room, the higher VOCs concentrations in the room with the same air change rate. Therefore, indoor air quality standard and furniture loading factor in the room should be considered simultaneously when determining furniture emission threshold. Loading factor of furniture in the room can be obtained through field measurement of furniture emission area and volume of the room. It is noted that buildings include many categories, such as residential buildings, office buildings and public buildings. Loading factors of furniture in these buildings may be very different because of their different functional requirements. This paper's investigation of loading factor of furniture concerned only residential buildings. Hence, threshold values in this study are for residential furniture. However research thought here are also suitable for office furniture and public furniture.

\subsection{Testing method}

The testing time of 7-28 d of existing labeling system is too long which leads to high testing cost that translates to a heavy economic burden on the manufacturers. This is not beneficial to popularizing and applying a labeling scheme. Model prediction could be used to predict long term emission performance of building materials according to short term test. For example, power-law model [18] proposed by BIFMA [19] could be used to estimate emission rate of fur- niture at day 14 based on test results at day 3 and day 7 . However, this model is empirical model, and it is only used to predict emission rate at day 14 or less [19]. Studies [20-22] show VOCs emission performance of building materials is characterized by three key parameters: initial emittable concentration, the diffusion coefficient, and the partition coefficient. Emission rate of building material could be calculated by using mass transfer model when these three parameters are given [23-27]. A lot of methods were developed to determine these three key parameters [28], among which C-history method proposed by Xiong et al. [29] is the most salient with features as follows: the three parameters can be simultaneously obtained; it is time-saving, generally taking less than $3 \mathrm{~d}$. Therefore, it is helpful by using C-history method to test the VOCs emissions from furniture to shorten the testing time.

\section{Research practices}

\subsection{VOCs emissions test of furniture}

Wood-based furniture is most widely used in China. For wood-based furniture, there are generally two kinds: (1) wood veneer furniture which is usually made of density board, wood veneer and paint; (2) board furniture which is made of particle board and melamine veneer. The two kinds of wood-based furniture were selected as the testing samples. Eight pieces of furniture have been tested in $30 \mathrm{~m}^{3}$ stainless steel chamber. The furniture is put in the static chamber until VOCs concentrations reach equilibrium, and then VOCs composition in the chamber air is determined [30]. Considering the sum of concentrations of formaldehyde and TVOC as the total concentration, the ratio of individual VOC concentration to the total concentration is obtained. Taking one piece of furniture for example, the VOCs composition is shown in Figure 1.

VOCs emissions from eight pieces of furniture are summarized. Frequency of every individual VOC is counted.

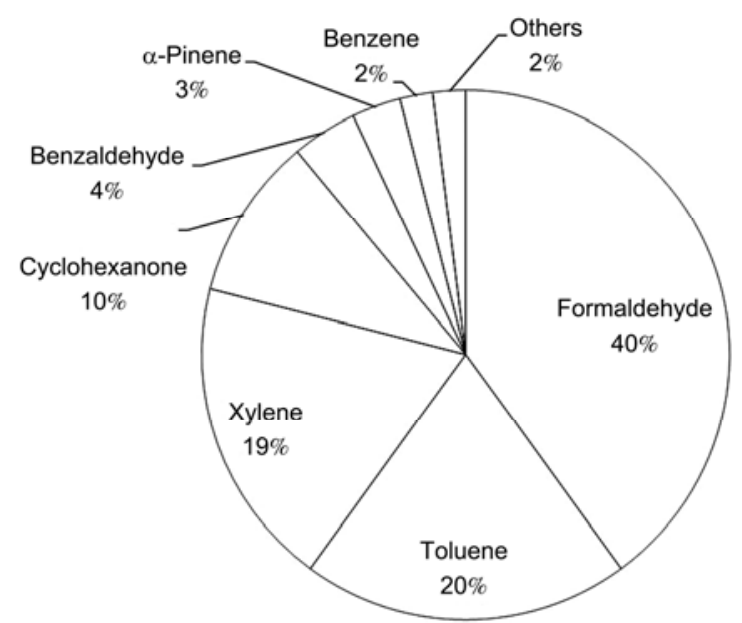

Figure 1 Compositions of pollutants emitted from furniture A. 
VOCs with higher frequency are listed in Table 1. From Table 1 we can see formaldehyde, benzene, toluene and xylene which are specified in national standard GB/T 188832002 are common pollutants from furniture. Additionally, there are ethylbenzene, cyclohexanone, benzaldehyde and $\alpha$-pinene emitted from furniture. Ethylbenzene is specified in national standard GB 50325-2010. Cyclohexanone, benzaldehyde and $\alpha$-pinene are specified in German AgBB labeling scheme [32] in which their lowest concentration of interest (LCI) are $0.41,0.09$, and $1.5 \mathrm{mg} / \mathrm{m}^{3}$ respectively. LCI of $\alpha$-pinene $\left(1.5 \mathrm{mg} / \mathrm{m}^{3}\right)$ is larger than threshold of TVOC $\left(0.60 \mathrm{mg} / \mathrm{m}^{3}\right)$ in GB/T $18883-2002$. TVOC is an indispensable target pollutant in indoor air quality standard. Therefore it is not necessary to concern $\alpha$-pinene.

\subsection{Calculation method of VOCs emission rate threshold values of furniture}

(i) Survey of furniture usage in homes. The 1500 homes in Beijing were randomly selected for the survey. The selected apartments are located in different districts of Beijing and cover a wide range of age and price [33]. The survey was composed of two parts: (1) a basic information questionnaire that includes questions such as the price of the apartment, the cost of renovation, the flooring material, the area of different rooms and the room height; (2) a measurement of the emission area of the wood-based furniture in different rooms. Based on the questionnaire feedback, the total floor area and the furniture loading factor distribution could be
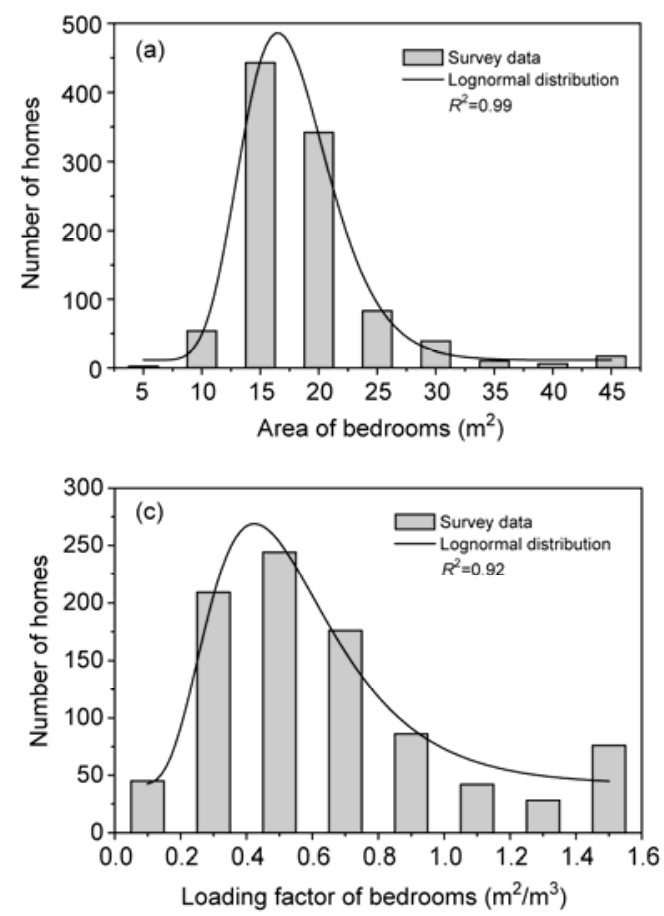

determined. The distribution of the room area and the loading factor of the furniture in different rooms are found to be in compliance with the lognormal distribution (Figure 2). The geometric mean values which stand for the representative values of the samples are listed in Table 2. The Monte Carlo method [34] was used to analyze the uncertainties of the representative values of the room area and furniture loading factors of bedroom and living room. The results show that the uncertainties of the parameters are controlled within $\pm 10 \%$ (Table 2) [33].

(ii) Establishment of two reference rooms. The floor area and the loading factor of the wood-based furniture are the two key parameters for a reference room. The calculated loading factor of furniture mentioned above is defined as

Table 1 Statistic of VOCs emissions from eight pieces of furniture [31]

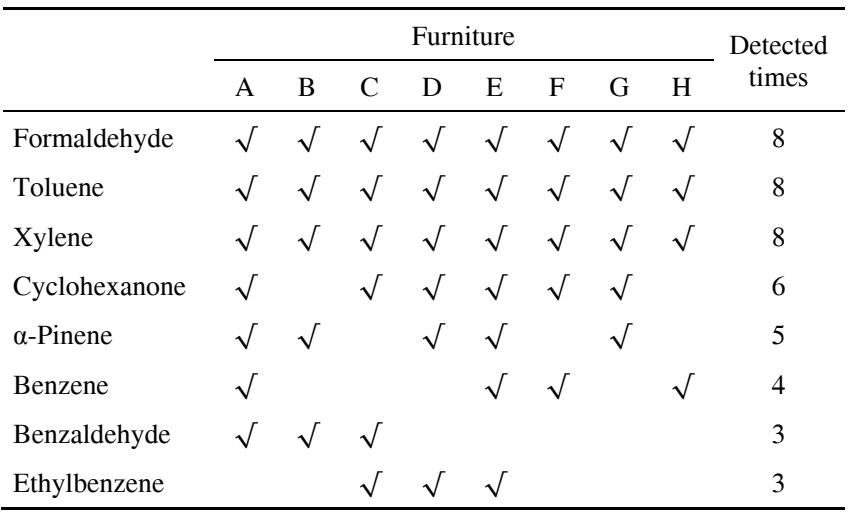
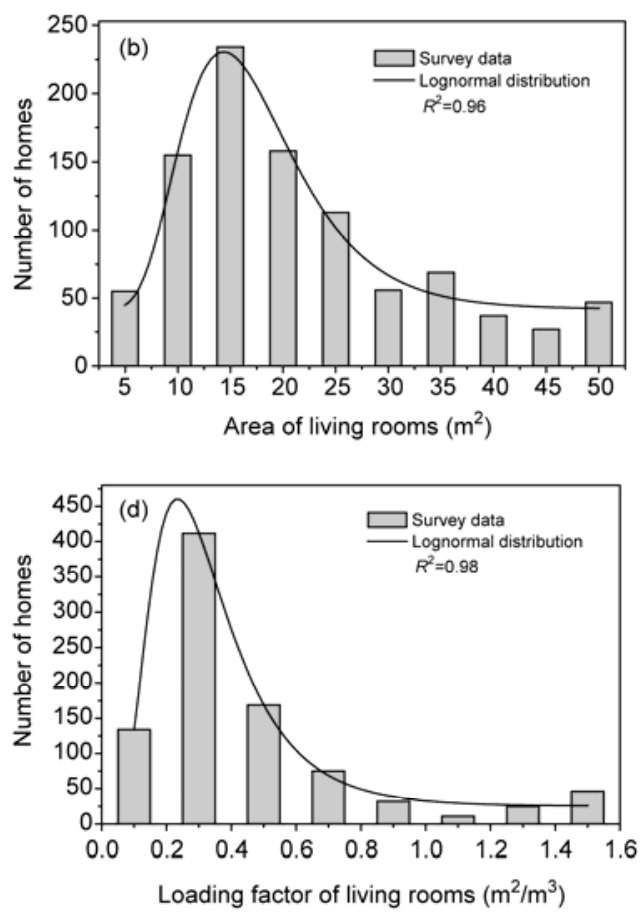

Figure 2 Curves of the lognormal distribution fitting. (a) Area of bedrooms; (b) area of living rooms; (c) loading factor of bedrooms; (d) loading factor of living rooms [31]. 
Table 2 Geometric mean values and their uncertainties of the lognormal distribution

\begin{tabular}{cccccc}
\hline & \multicolumn{2}{c}{ Floor area $\left(\mathrm{m}^{2}\right)$} & & \multicolumn{2}{c}{ Loading factor $\left(\mathrm{m}^{2} / \mathrm{m}^{3}\right)$} \\
\cline { 2 - 3 } \cline { 5 - 6 } & Bedroom & Living room & & Bedroom & Living room \\
\hline Geometric mean & $16.5 \pm 0.8$ & $22.0 \pm 1.1$ & & $0.42 \pm 0.04$ & $0.23 \pm 0.02$ \\
\hline
\end{tabular}

the emission area per room volume. When establishing the reference room, another loading factor is introduced which takes the floor area into account. This loading factor assumes the floor area to be made of wood and it is added into emission area. Furniture type and number are also essential information for a reference room. The information for these parameters for a bedroom and living room are summarized from the questionnaires. The corresponding reference rooms are established (Table 3 and Figure 3).

(iii) Determination of the threshold. Furniture test was carried on in full-scale chamber. Assume: (1) the air in the chamber is well mixed; (2) no absorption effect of the inner surface of the chamber; (3) no chemical reaction in the chamber; (4) no leakage; and (5) inlet air is purified. The concentration of any VOC emitted from the furniture is governed by the following mass balance equation:

$$
V \frac{\mathrm{d} C}{\mathrm{~d} t}=E A-Q C,
$$

where $V$ is chamber volume $\left(\mathrm{m}^{3}\right), C$ is the VOC concentration in the chamber $\left(\mathrm{mg} / \mathrm{m}^{3}\right), E$ is the VOC emission factor of the testing specimen $\left(\mathrm{mg} /\left(\mathrm{m}^{2} \mathrm{~h}\right)\right), A$ is the emission surface area of the specimen $\left(\mathrm{m}^{2}\right)$, and $Q$ is the air flow rate $\left(\mathrm{m}^{3} / \mathrm{h}\right)$.

When the steady-state is reached, eq. (1) could be simplified to eq. (2) to calculate emission rate.

$$
E=\frac{N}{L} C,
$$

where $N$ is the air change rate $\left(\mathrm{h}^{-1}\right)$, and $L$ is the loading factor $\left(\mathrm{m}^{2} / \mathrm{m}^{3}\right)$.

When the indoor air standard value is applied as $C$, loading factor from the survey is applied as $L$, and we set the $N$ of the reference room to be $1 \mathrm{~h}^{-1}$ which is from Chinese national standard JGJ 75-2003 [35], $E$ could be regarded as

\begin{tabular}{|c|c|c|}
\hline Parameters & Reference bedroom & Reference living room \\
\hline Volume $\left(\mathrm{m}^{3}\right)$ & $16.5 \times 2.6=42.9$ & $22 \times 2.6=57.2$ \\
\hline Flooring $\left(\mathrm{m}^{2}\right)$ & 16.5 & 22.0 \\
\hline Door $\left(\mathrm{m}^{2}\right)$ & $0.8 \times 2=1.6$ & $0.8 \times 2=1.6$ \\
\hline Window $\left(\mathrm{m}^{2}\right)$ & $1.8 \times 1.5=2.7$ & $1.8 \times 1.5=2.7$ \\
\hline Loading factor without floor $\left(\mathrm{m}^{2} / \mathrm{m}^{3}\right)$ & 0.42 & 0.23 \\
\hline Furniture inside & $\begin{array}{l}1 \text { Double-bed } \\
2 \text { Bedside cabinets } \\
1 \text { Wardrobe } \\
1 \text { Dresser } \\
1 \text { Chair } \\
1 \text { Other cabinet }\end{array}$ & $\begin{array}{l}1 \text { Sofa } \\
1 \text { Tea table } \\
1 \text { TV cabinet } \\
1 \text { Dinner table } \\
4 \text { Chairs } \\
1 \text { Cabinet }\end{array}$ \\
\hline
\end{tabular}

Table 3 Parameters of the two reference rooms [31]

(a)

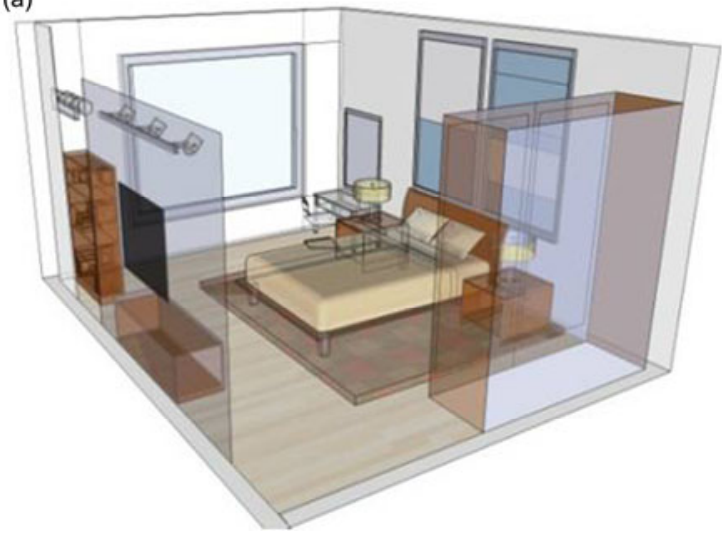

(b)

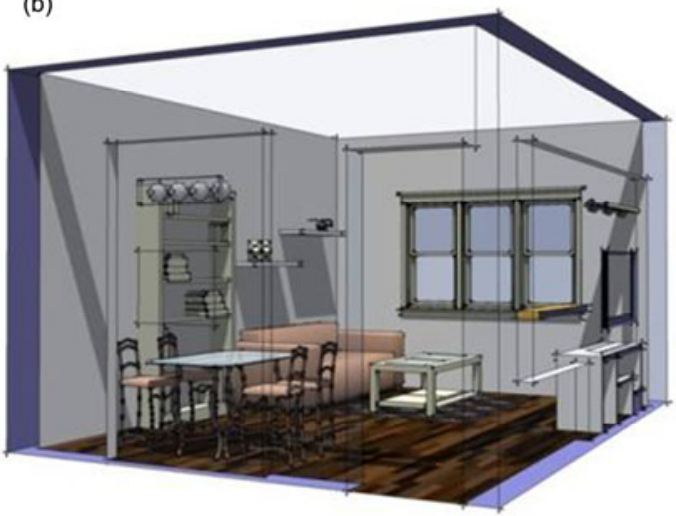

Figure 3 (Color online) Reference bedroom (a) and living room (b). 
the emission factor threshold of furniture in the chamber test. The emission factor thresholds of different target VOCs specified in GB/T 18883-2002 are calculated accordingly (Table 4).

\subsection{A rapid measurement method of VOCs emissions from furniture}

(i) Chamber. A full-scale stainless steel chamber of $30 \mathrm{~m}^{3}$ was constructed by Tsinghua University to test furniture (Figure 4) [36]. Its design indicators refer to American standard ASTM D6670 [37]. Three parts of the chamber are well designed which are chamber system, air purification system, and temperature and humidity control system. This chamber could be used to carry out VOCs emissions tests with its performances as follows: air leakage of the chamber was $0.019 \mathrm{~h}^{-1}$; mixing level was $87 \%$; temperature and relative humidity control precisions were $\pm 0.5^{\circ} \mathrm{C}$ and $\pm 5 \%$

Table 4 VOCs emission factor thresholds of furniture [31]

\begin{tabular}{lcccc}
\hline & Formaldehyde & TVOC & Benzene & Toluene \\
\hline GB/T $18883-2002\left(\mathrm{mg} / \mathrm{m}^{3}\right)$ & 0.10 & 0.60 & 0.11 & 0.20 \\
$E_{B}{ }^{\text {a) }}\left(\mathrm{mg} /\left(\mathrm{m}^{2} \mathrm{~h}\right)\right)$ & 0.14 & 0.86 & 0.16 & 0.20 \\
$E_{L}^{\text {b) }}\left(\mathrm{mg} /\left(\mathrm{m}^{2} \mathrm{~h}\right)\right)$ & 0.24 & 1.43 & 0.26 & 0.29 \\
\hline
\end{tabular}

a) Emission rate thresholds of furniture in bedroom; b) emission rate thresholds of furniture in living room.

(a)

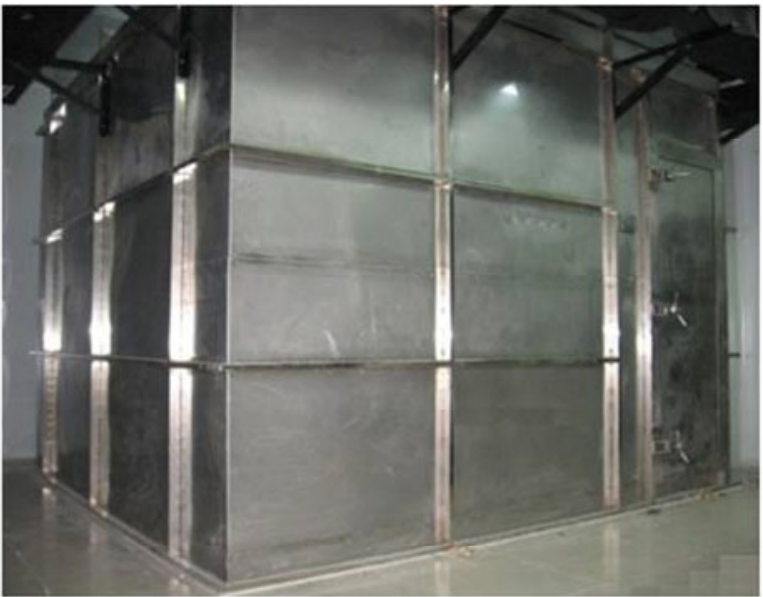

(b)

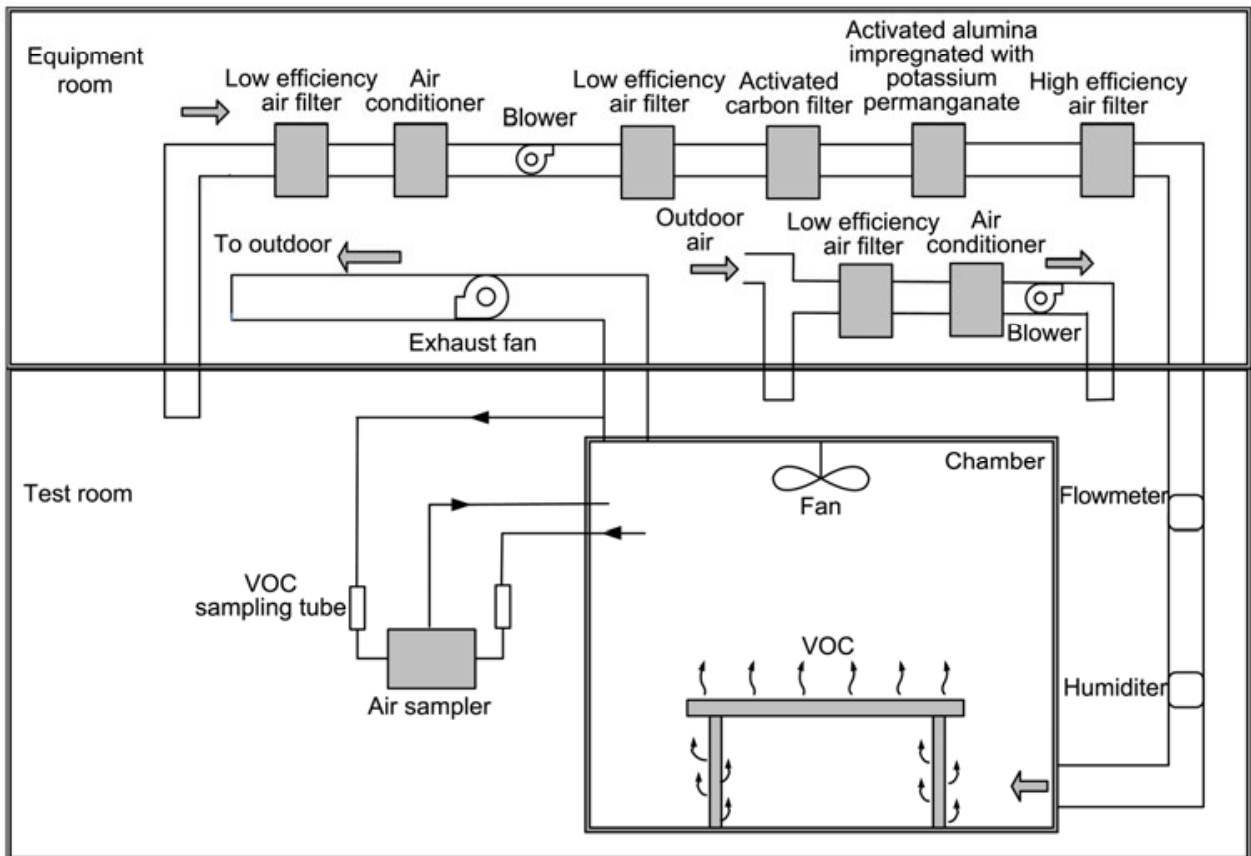

Figure 4 (Color online) $30 \mathrm{~m}^{3}$ full-scale chamber. (a) Photo of the chamber; (b) system diagram. 
respectively; and the background concentration was less than $10 \%$ of the standard value.

(ii) Reference sample. A reference sample is needed to calibrate the chamber system before real furniture emission test. Wei et al. [38] developed a new kind of reference sample LIFE (liquid-inner tube diffusion-film-emission). The reference is comprised of a cylinder with a diameter of $40 \mathrm{~mm}$ and a length of $40 \mathrm{~mm}$ to hold a single, purified VOC in liquid state as the emission source, a thin diffusion film to cover the opening of the cylinder to control the emission rate, and fastening pieces to hold the cylinder and film in place (Figure 5). A reference sample is placed in a ventilated chamber with temperature of $23 \pm 0.5^{\circ} \mathrm{C}$ and relative humidity of $50 \pm 5 \%$. Two microbalances with accuracy of $0.0001 \mathrm{~g}$ are used to measure the mass of the sample independently twice a day. The experiment shows the LIFE reference could emit constantly for at least $1000 \mathrm{~h} \mathrm{[38].}$

(iii) C-history method. Xiong et al. [39] obtained an analytical solution describing VOCs emissions from building materials in a static chamber. Based on this analytical solution, a new method, the C-history method for a closed chamber, to measure the three parameters simultaneously (i.e., the initial emittable VOC concentration, the partition coefficient, and the diffusion coefficient) is developed [29]. The principle of the C-history method is as follows. When building material is put into the static chamber, the VOC concentration in the chamber would increase until it reaches equilibrium concentration. Based on the analytical solution describing VOC emission, the following equation can be derived [28]:

$$
\begin{gathered}
\ln \left(\frac{C_{\text {equ }}-C_{a}(t)}{C_{\text {equ }}}\right)=-D_{m} L^{-2} q_{1}^{2} t+\ln \left(-\frac{2(K \beta+1) \sin q_{1}}{q_{1} A_{1}}\right), \\
C_{\text {equ }}=\frac{C_{m, 0} \beta}{K \beta+1},
\end{gathered}
$$

where $C_{a}(t)$ is the chamber VOC concentration $\left(\mathrm{mg} / \mathrm{m}^{3}\right)$, $C_{m, 0}$ is the initial emittable concentration of VOC in the furniture $\left(\mathrm{mg} / \mathrm{m}^{3}\right), C_{\text {equ }}$ is the equilibrium chamber VOC concentration $\left(\mathrm{mg} / \mathrm{m}^{3}\right), D_{m}$ is the diffusion coefficient $\left(\mathrm{m}^{2} / \mathrm{s}\right), K$ is the partition coefficient, $\beta=A L / V, L$ is the thickness of the

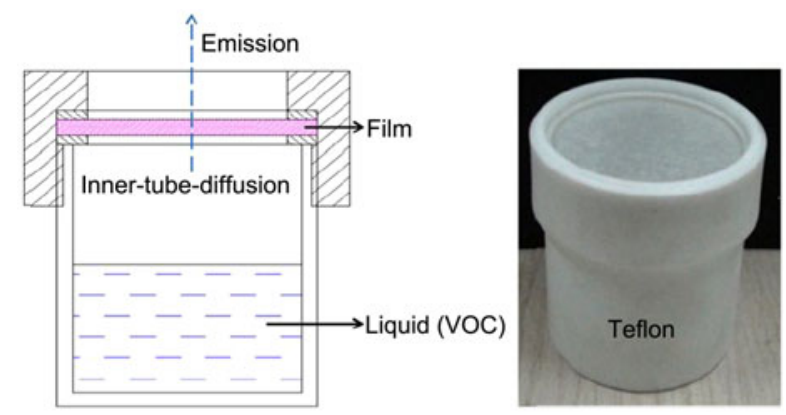

Figure 5 (Color online) Schematic of a reference sample [38]. building material (m), $A$ is the area of the building material $\left(\mathrm{m}^{2}\right), V$ is the volume of the chamber $\left(\mathrm{m}^{3}\right), A_{l}=(K \beta$ $\left.q_{1}^{2} K B i_{m}^{-1}+1\right) \cos q_{1}-\left(1+2 K B i_{m}^{-1}\right) q_{1} \sin q_{1}, B i_{m}$ is the biot number for mass transfer $\left(B i_{m}=h_{m} L / D_{m}\right), h_{m}$ is the convective mass transfer coefficient $(\mathrm{m} / \mathrm{s})$, and $q_{1}$ is the first positive root of the eq. (5).

$$
\frac{\tan q_{1}}{q_{1}}=\frac{1}{q_{1}^{2} K B i_{m}^{-1}-K \beta} .
$$

If the chamber VOC concentration is treated as the form of the logarithm of dimensionless excess concentration in eq. (3), the slope and intercept can be obtained by doing linear curve fitting. The two parameters $D_{m}$ and $K$ can be obtained directly because they are functions of slope and intercept, and we have two equations with two unknown parameters. Combining eq. (4) and the known value of $K$, $C_{m, 0}$ can be calculated. Applying these parameters obtained in emission model of dynamic chamber [24], emission rate of building materials in any ventilation conditions could be calculated. Through a series of case studies, Yao et al. [30] found that wood-based furniture could be approximated to single-layer board, thus C-history method is extended to determine equivalent initial emittable concentration, partition coefficient and diffusion coefficient of VOCs emissions from wood- based furniture. By treating the chamber VOC concentration in the closed chamber according to eq. (3), we could get the linear curve fitting results for formaldehyde in the furniture (Figure 6). Validations of the determined parameters were performed both in a closed chamber and in a ventilated chamber. Figure 7 shows that the agreement between the simulated results and experimental data is satisfactory for both the closed and ventilated chambers. This means for the wood-based furniture, it is possible to use C-history method to shorten the testing time.

\subsection{Evaluation procedures of furniture labeling scheme}

It is shown in Figure 8 how to label the furniture. First,

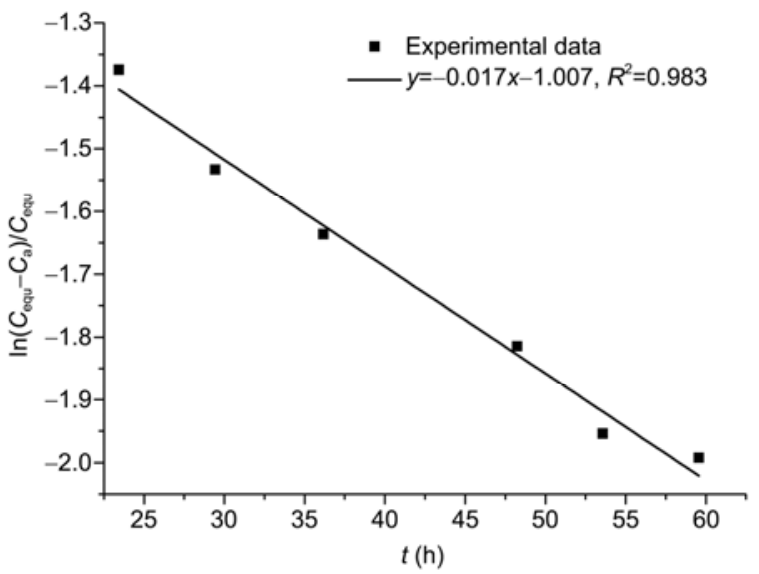

Figure 6 Linear curve fitting of formaldehyde [30]. 

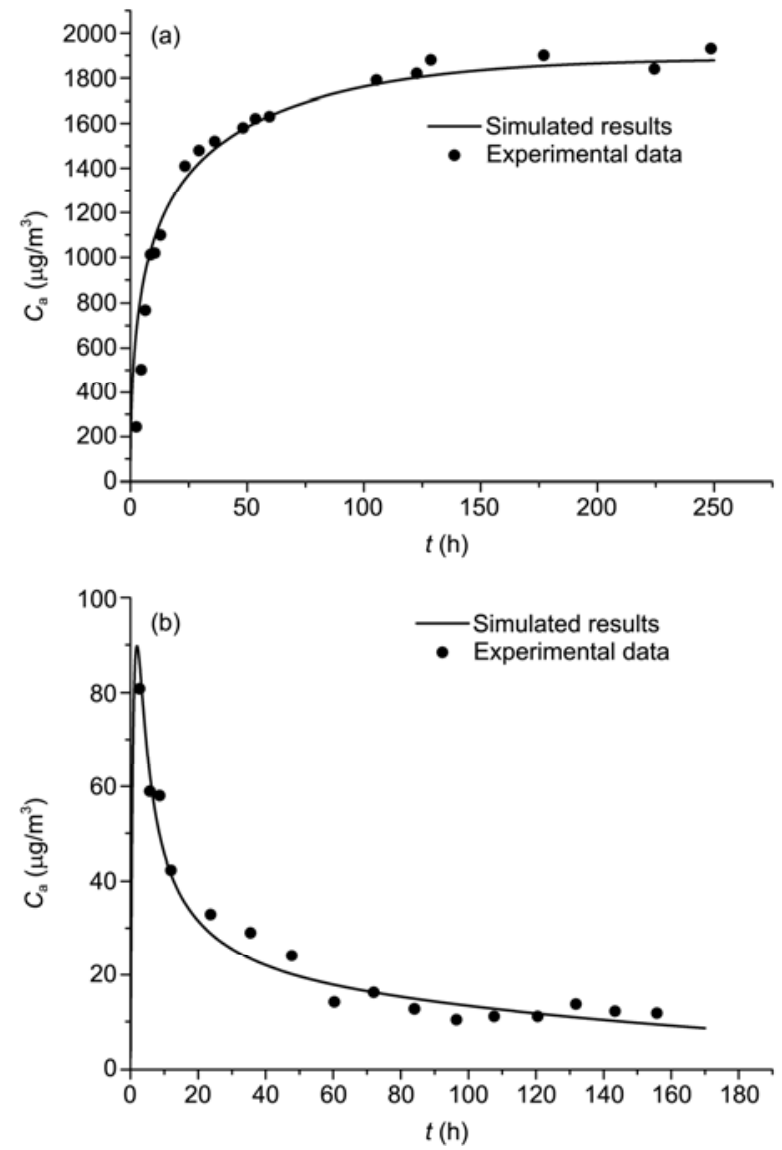

Figure 7 Comparison of the simulated results with the experimental data for the chamber formaldehyde concentrations. (a) Closed chamber; (b) ventilated chamber [30].

Specimen $\longrightarrow$ Test $\longrightarrow$ Evaluation $\longrightarrow$ Label

Figure 8 Flowchart of furniture labeling scheme.

specimen is selected for testing which should be representative of the products manufactured under typical operating conditions by professionals from furniture labeling certification organization. The selected furniture must be tightly packed with airtight packaging material (e.g., polyethylene bag) at the time of sample collection to prevent contamination and to limit subsequent VOC emission losses. Then the packaged sample should be transported to the laboratory which is designated by certification organization as soon as possible. After the package is received by laboratory, it could be stored without unpacking for a short time, or unpacked and then immediately moved into the chamber to be installed for testing with C-history method mentioned above in this paper. According to testing results VOC emission rates of furniture can be calculated. In evaluation step, professionals from certification organization will check testing results of VOC emission rates of specimen. If testing results are not more than threshold values, the furniture will get the label, or it will be rejected.

\section{Conclusions}

(1) The test results of furniture commonly found in the market show that formaldehyde, benzene, toluene and xylene specified in the national standard GB/T 18883-2002 are main pollutants from furniture. In addition, ethylbenzene, cyclohexanone and benzaldehyde are also common pollutants and should be concerned.

(2) A survey of 1500 homes found that the distribution of the room area and the loading factor of the furniture in rooms are in compliance with the lognormal distribution. Two reference rooms, a reference bedroom and a reference living room are recommended according to the survey results. Based on the established reference rooms and the national indoor air quality standard GB/T 18883-2002, the emission factor thresholds of VOCs were calculated.

(3) A series of cases studies show that commonly used wood-based furniture could be approximately regarded to be single-layer board. Therefore, the C-history method provides a possible choice to shorten the testing time of VOCs emissions from furniture to within 3 days.

(4) A LIFE reference shows a constant emission rate in the typical furniture emission range under standard temperature and humidity conditions. It can be directly applied in a full-scale chamber to evaluate the performance of the chamber system.

This work was supported by Beijing Municipal Science and Technology Commission Projects (D09050603750802) and the Chinese National 12th Five-year Science and Technology Support Plan Project (2012BAJ02B01).

1 Missia D A, Demetriou E, Michael N, et al. Indoor exposure from building materials: A field study. Atmos Environ, 2010, 44: 43884395

2 Guo H, Kwok N H, Cheng H R, et al. Formaldehyde and volatile organic compounds in Hong Kong homes: Concentrations and impact factors. Indoor Air, 2009, 19: 206-217

3 Chan C S, Lee S C, Chan W, et al. Characterisation of volatile organic compounds at hotels in southern China. Indoor Built Environ, 2011, 20: 420

4 Zhang L Z, Niu J L. Modeling VOCs emissions in a room with a single-zone multi-component multi-layer technique. Build Environ, 2004, 39: 523-531

5 Ministry of Housing and Urban-Rural Development of the People's Republic of China. GB 50325-2010, Code for indoor environmental pollution control of civil building engineering (in Chinese). 2010

6 General Administration of Quality Supervision, Inspection and Quarantine of the People's Republic of China. GB/T 18883-2002, Indoor air quality standard (in Chinese). 2002

7 Spengler J D, Samet J M, McCarthy J F. Indoor Air Quality Handbook. New York: McGraw-Hill Companies, 2001

8 Liu W W, Zhang Y P, Yao Y, et al. Indoor decorating and refurbishing materials and furniture volatile organic compounds emission labeling systems: A literature review. Chin Sci Bull, 2012, 57: 2533-2543

9 Kephalopoulos S, Koistinen K, Kotzias D. Report No.24-Harmonisation of indoor material emissions labelling systems in the EU: Inventory of existing schemes. Technical Report, European Collaborative Action, European Commission. 2005

10 Müller B, Dahms A, Bitter F, et al. Material labelling: Combined 
material emission tests and sensory evaluations. In: Strøm-Tejsen P, Olesen B W, Wargocki P, et al., eds. Proceedings of the 11th international conference on indoor air quality and climate, 2008 Aug 17-22, Copenhagen. Denmark: Technical University of Denmark, 2008. 1066

11 Neuhaus T, Oppl R. Comparison of emission specifications in the US and in Europe. In: Strøm-Tejsen P, Olesen B W, Wargocki P, et al., eds. Proceedings of the 11th International Conference On Indoor Air Quality And Climate, 2008 Aug 17-22, Copenhagen. Denmark: Technical University of Denmark, 2008. 954

12 Crump D, Däumling C, Winther-Funch L, et al. Report No.27Harmonisation framework for indoor material labelling schemes in the EU. Technical Report, European Collaborative Action, European Commission. 2010

13 Wolkoff P. Trends in Europe to reduce the indoor air pollution of VOCs. Indoor Air, 2003, 13: 5-11

14 He Z K, Wei W J, Zhang Y P. Formaldehyde and VOC emissions at different manufacturing stages of wood-based panels. Build Environ, 2012, 47: 197-204

15 Yu C W F, Crump D R. Small chamber tests for measurement of VOC emissions from flooring adhesives. Indoor Built Environ, 2003, 12: $299-310$

16 Salthammer T. Emission of volatile organic compounds from furniture coatings. Indoor Air, 1997, 7: 189-197

17 General Administration of Quality Supervision, Inspection and Quarantine of the People's Republic of China. GB 18584-2001, Indoor decorating and refurbishing materials-Limit of harmful substances of wood based furniture (in Chinese). 2001

18 Zhu J P, Zhang J S, Shaw C Y. Comparison of models for describing measured VOC emissions from wood-based panels under dynamic chamber test condition. Chemosphere, 2001, 44: 1253-1257

19 American National Standards Institute (ANSI). ANSI/BIFMA M7.12007, Standard test method for determining VOC emissions from office furniture systems, components and seating. 2007

20 Little J C, Hodgson A T, Gadgil A J. Modeling emissions of volatile organic compounds from new carpets. Atmos Environ, 1994, 28: 227234

21 Yang X D, Chen Q Y, Zhang J S, et al. Numerical simulation of VOC emissions from dry materials. Build Environ, 2001, 36: 1099-1107

$22 \mathrm{Xu} \mathrm{Y,} \mathrm{Zhang} \mathrm{Y} \mathrm{P.} \mathrm{An} \mathrm{improved} \mathrm{mass} \mathrm{transfer} \mathrm{based} \mathrm{model} \mathrm{for}$ analyzing VOC emissions from building materials. Atmos Environ, 2003, 37: 2497-2505

23 Xu Y, Zhang Y P. A general model for analyzing VOC emission characteristics from building materials and it's application. Atmos Environ, 2004, 38: 113-119

24 Deng B Q, Kim C N. An analytical model for VOC emission from dry building materials. Atmos Environ, 2004, 38: 1173-1180

25 Wang X K, Zhang Y P, Zhao R Y. Study on characteristics of double surface VOC emissions from dry flat-plate building materials. Chin
Sci Bull, 2006, 51: 2287-2293

26 Hu H P, Zhang Y P, Wang X K, et al. An analytical mass transfer model for predicting VOC emissions from multi-layered building materials with convective surfaces on both sides. Int J Heat Mass Transfer, 2007, 50: 2069-2077

27 Wang X K, Zhang Y P. General analytical mass transfer model for VOC emissions from multi-layer dry building materials with internal chemical reactions. Chin Sci Bull, 2011, 56: 222-228

28 Xiong J Y. VOC emission characteristics from building materials: Measurement, micro-mesocosmic interpretation and simulation (in Chinese). PhD Thesis. Beijing: Tsinghua University, 2010. 3-13

29 Xiong J Y, Yao Y, Zhang Y P. C-history method: Rapid measurement of the initial emittable concentration, diffusion and partition coefficients for formaldehyde and VOCs in building materials. Environ Sci Technol, 2011, 45: 3584-3590

30 Yao Y, Xiong J Y, Liu W W, et al. Determination of the equivalent emission parameters of wood-based furniture by applying C-history method. Atmos Environ, 2011, 45: 5602-5611

31 Liu W W, Zhang Y P, Yao Y. Research on determination of target pollutants and their threshold values of furniture VOCs labeling scheme (in Chinese). Build Sci, 2012, 28: 49-51

32 German Committee for Health-related Evaluation of Building Products (AgBB). A contribution to the construction products directive: Healthrelated evaluation procedure for volatile organic compounds emissions (VOC and SVOC) from building products. 2010

33 Liu W W, Yao Y, Zhang Y P. Determination of the thresholds of typical indoor pollutants from furniture emission in full-scale chamber. In: The 12th International Conference on Indoor Air Quality and Climate, 2011 June 5-10, Austin, Texas, 2008. 718

34 Kim E, Little J C, Chiu N. Estimating exposure to chemical contaminants in drinking water. Environ Sci Technol, 2004, 38: 1799-1806

35 Ministry of Housing and Urban-Rural Development of the People's Republic of China. JGJ 75-2003, Design standard for energy efficiency of residential buildings in hot summer and warm winter zone (in Chinese). 2003

36 Liu W W, Zhang Y P, Yao Y, et al. Design and evaluation of fullscale chamber for determination chemical contaminant emissions from indoor materials/products (in Chinese). Build Sci, 2010, 26: 40-45

37 American Society for Testing and Materials (ASTM). ASTM D667001 (Reapproved 2007), Standard practice for full-scale chamber determination of volatile organic emissions from indoor materials/ products. 2007

38 Wei W J, Zhang Y P, Xiong J Y, et al. A standard reference for chamber testing of material VOC emissions: Design principle and performance. Atmos Environ, 2012, 47: 381-388

39 Xiong J Y, Zhang Y P, Huang S D. Characterisation of VOC and formaldehyde emission from building materials in a static environmental chamber: Model development and application. Indoor Built Environ, 2011, 20: 217-225

Open Access This article is distributed under the terms of the Creative Commons Attribution License which permits any use, distribution, and reproduction in any medium, provided the original author(s) and source are credited. 